\title{
Older Adults Used Fewer Home Care Services during the COVID-19 Pandemic: Findings from a Secondary Analysis of an Urgent Survey in Japan
}

\author{
Hiroshige Matsumoto ${ }^{1}$, Masahiro Kawagoe ${ }^{2}$, Satoko Hotta ${ }^{3}$ \\ ${ }^{1}$ Department of Community Health Nursing, Graduate School of Medicine, The University of Tokyo, Tokyo, Japan \\ ${ }^{2}$ Graduate Course of Health and Social Services, Saitama Prefectural University, Saitama, Japan \\ ${ }^{3}$ Graduate School of Health Management, Keio University, Kanagawa, Japan
}

\section{Corresponding Author:}

Hiroshige Matsumoto, MS

Department of Community Health

Nursing, Graduate School of Medicine,

The University of Tokyo, Tokyo, Japan

E-mail: hiroshige-tky@g.ecc.u-tokyo.ac.jp ORCID:

https://orcid.org/0000-0002-7608-5552

Received: September 14, 2021

Revised: October 29, 2021

Accepted: November 4, 2021

\begin{abstract}
Background: This study aimed to identify reduced home care use among older people and its impact on user numbers and service provider revenues during the coronavirus disease 2019 (COVID-19) pandemic. Methods: We conducted this secondary analysis of cross-sectional data from long-term care providers in Japan and estimated the probability of client cancellations and service contraction for institutional and home care services adjusted for the service type, area, size, infection occurrence, and staff employment impacts. We then estimated the rate of change in user numbers and revenue related to reduced usage. Results: Seventy-two percent of home care providers experienced client cancellations and $42.1 \%$ experienced service contraction, both of which were more prevalent in home care than in institutional care (adjusted odds ratio $[A O R]=11.09$ and 1.60). Home-visit $(A O R=0.70)$ and short-term stay $(A O R=0.38)$ services were less likely to experience client cancellations compared with adult day services. Service contraction was less likely in home-visit services $(\mathrm{AOR}=0.60)$ but were more likely in short-stay services $(A O R=1.49)$ compared to adult day services. The estimated reductions in user numbers and revenue related to service contraction for adult day services were $9.1 \%$ and $7.1 \%$, respectively. Home-visiting services decreased by an estimated $3.4 \%$ owing to service contraction. Conclusion: The secondary effects of the COVID-19 pandemic include reduced use of home care services, especially adult day services that include social contact. These secondary effects of the COVID-19 pandemic may cause functional deterioration in non-infected clients and financially impact senvice providers.
\end{abstract}

Key Words: Adult day care centers, COVID-19, Home care services, Long-term care, Respite care

\section{INTRODUCTION}

Older adults are vulnerable to both coronavirus disease 2019 (COVID-19) and the secondary effects of the pandemic. ${ }^{1)}$ Given the lack of effective pharmacological treatment, home isolation has been recommended to prevent infection, ${ }^{2)}$ which raises concerns regarding the secondary effects on older people living in the community, including reduced physical activity, social isolation, and reduced access to home care services. ${ }^{3-5)}$

Older people living in the community face additional challenges related to reduced home care. ${ }^{6,7)}$ Even in facilities in which no outbreaks have occurred, home care has been reduced or suspended because employees are required to stay home to prevent the spread of infection and thus are unable to provide care. ${ }^{8,9)}$ Families are reluctant to send older people to long-term care (LTC) facilities, ${ }^{8)}$ which causes confusion and stress not only to clients but also to family caregivers. The symptoms of people with dementia may also be aggravated by disruptions in their usual lifestyle and prolonged indoor living. ${ }^{1,10)}$ Furthermore, a significant decrease in user numbers negatively affects home LTC provider businesses. ${ }^{11)}$ 
However, little is known about how reduced use affects home care. $^{7)}$

In Japan, the Ministry of Health, Labour and Welfare restricted visits to clients in LTC facilities from February 24, 2020, before a steep increase in the number of cases. ${ }^{12)}$ In early March, the first outbreak at an adult day service was identified, following which other LTC providers in the area were required to close. ${ }^{9)}$ In late March, the number of infections increased, and on April 1, the government's expert panel recommended suspending or restricting day care services for persons with disability. ${ }^{13)}$ A survey of home LTC providers conducted in April showed that $25.6 \%$ of respondents had experienced decreases of income of $20 \%$ or more in March compared to those in February. ${ }^{11)}$ On April 7, a state of emergency was declared for seven prefectures, which was gradually expanded. One percent or more of the adult day services for people with disabilities were closed during this period. ${ }^{14)}$ A total of 39 LTC facilities had experienced outbreaks by May $9 .{ }^{15)}$

This study investigated the reduced use of home LTC services using data from an urgent survey of LTC providers in Japan. Reduced usage in this study included both client cancellations (i.e., users voluntarily refraining from using the service) and service contraction (i.e., service providers reducing service availability). To evaluate the magnitude of the effects on home care, we compared the impact of home care services to that of institutional services and assessed which of these home care services were more likely to be affected. The research questions were as follows. (1) Were home LTC services more likely to experience reduced usage than institutional LTC services during the COVID-19 pandemic? Which home LTC services were the most affected? (2) To what extent did reduced usage affect user numbers and provider revenues for each service?

\section{MATERIALS AND METHODS}

\section{Data}

We conducted this secondary analysis of survey data from the Urgent Survey on the Impact of COVID-19 on Long-term Care and Support for Older Adults and Practices and Innovations in the Field. This web-based survey was conducted by members of the Long-Term Care Benefit Expense Subcommittee of the Social Security Council through 15 national associations of LTC providers in Japan. From May 12 to 22, 2020, a total of 6,130 providers responded to the survey. The survey was anonymously conducted, with participant contact information collected voluntarily only when the participants agreed to follow-up surveys. A report of the main survey has already been published. ${ }^{16)}$ We obtained the anonymized data, and ethical approval was not required to obtain these data because they are not participant-identifiable.

\section{Subjects}

The analysis included institutional and home care services covered by public LTC insurance. The institutional care services included nursing homes, geriatric health service facilities, and group homes. The home care services included adult day, home visit, and short stay services.

\section{Research Question 1}

Multivariate logistic regression analysis was conducted with usage reduction as the dependent variable and each service category (i.e., institutional or home care, adult day service, home visit service, or short stay service) as an independent variable. Usage reduction included two categories: client cancellations initiated by clients or their families and service contraction in which service providers reduced or stopped service availability. Client cancellations were measured by a single item asking providers whether they had experienced any cancellation by clients or families. Service contracts were measured using items such as facility closure owing to local governmental request or facility decision, provider requests that users refrain from using the facility, restriction or suspension of new users, and reduced daily service hours. Providers who experienced one or more of these situations were categorized as having experienced service contraction.

We adjusted for three types of variables: (1) service size (because a larger provider is more likely to experience reduced service); (2) service area (because organizations participating in the survey differed in the types of service offered and regional response rates); and (3) occurrence or suspicion of COVID-19 infection among clients, family members, or staff and the impact of COVID-19 on staff employment as they were strong predictors of service reduction. The service size was categorized as $(1)<10$ fulltime equivalent (FTE) employees, (2) 10-30 FTE, and (3) $\geq 30$ FTE. Areas were categorized based on prefectural alert levels: (1) seven prefectures, including Tokyo, where a state of emergency was declared on April 7, (2) six prefectures that were added to the list of specified prefectures on April 16, and (3) another 34 prefectures where a state of emergency was declared on April 16 and where earlier categories indicated an earlier infection spread. The occurrence/suspicion of COVID-19 among clients or family was measured based on whether any client or family member had tested positive for or was suspected of having COVID-19 or had close contact with someone with COVID-19. The occurrence/suspicion of COVID-19 among staff was measured based on whether any staff member had tested positive for infection or had close contact with someone with COVID-19. The impact on staff em- 
ployment included employment restrictions, absence or retirement related to infection, fear of infection, or increased childcare and housework of employees.

\section{Research Question 2}

A multiple linear regression analysis was conducted for each service, with the change rate in the user numbers and revenue compared to the previous year as dependent variables and client cancellations and service contraction as independent variables adjusted for service size. This approach was adopted because the data did not include the number of clients with reduced usage and because a simple comparison to the previous year could not distinguish between the time trend and the effect of reduced usage. We retrospectively collected data on the numbers of users in April 2019 and April 2020 and calculated the rate of change by dividing the latter by the former. The participants directly provided their revenue rate of change in April 2020 compared to April 2019. We excluded cases with missing values for each analysis.

\section{RESULTS}

\section{Participant Characteristics}

A total of 6,171 responses were obtained. After excluding cases with missing variables, the analyses included 5,089 responses. The numbers of institutional care, adult day service, short stay service, and home visiting service clients were 2,569, 844, 217, and 1,459, respectively.
Table 1 shows the characteristics of the participating providers. More than half of the institutional care (63.3\%) and short stay service $(61.8 \%)$ providers were large scale providers, with smaller proportions of adult day service (5.2\%) and home visiting service (1.6\%) providers. The number of respondents from high-alert areas was larger for home visit services (46.8\%) and smaller for short stay services (23.0\%). Infection and suspected cases occurred more frequently in home visit services (29.3\%). Less than $2.2 \%$ of providers had infection or contact with COVID-19 patients for all services. More than $50 \%$ of participants reported impacts on staff employment in all services.

\section{Client Cancellations and Service Contraction}

Thirty-one percent of institutional care providers and $72.0 \%$ of home care providers experienced client cancellations. Table 2 shows the prevalence of reduced usage and the results of the logistic regression analysis with client cancellations and service contraction as dependent variables. Service type was significantly associated with client cancellations, with an adjusted odds ratio (AOR) of 11.09 .

Service contraction occurred in $38.2 \%$ of institutional care and $42.1 \%$ of home care providers. While service contraction was significantly more likely to occur in home care, the AOR of 1.60 was lower than that for client cancellations. Among home care services, adult day service had the highest rate of client cancellation (76.7\%). Short stay services were less likely to experience client cancellations $(\mathrm{AOR}=0.38)$ than adult day services but were more

Table 1. Service provider characteristics

\begin{tabular}{|c|c|c|c|c|c|}
\hline & $\begin{array}{c}\text { Institutional } \\
(\mathrm{n}=2,569)\end{array}$ & $\begin{array}{l}\text { Home care } \\
(\mathrm{n}=2,520)\end{array}$ & $\begin{array}{l}\text { Adult day } \\
(\mathrm{n}=844)\end{array}$ & $\begin{array}{l}\text { Short stay } \\
(\mathrm{n}=217)\end{array}$ & $\begin{array}{l}\text { Home visiting } \\
(\mathrm{n}=1,459)\end{array}$ \\
\hline \multicolumn{6}{|l|}{ Service size } \\
\hline Small & $217(8.4)$ & $1,600(63.5)$ & $473(56.0)$ & $30(13.8)$ & $1,097(75.2)$ \\
\hline Mid & $650(25.3)$ & $719(28.5)$ & $327(38.7)$ & $53(24.4)$ & $339(23.2)$ \\
\hline Large & $1,702(66.3)$ & $201(8.0)$ & $44(5.2)$ & $134(61.8)$ & $23(1.6)$ \\
\hline \multicolumn{6}{|l|}{ Area } \\
\hline With mid alert & $389(15.1)$ & $361(14.3)$ & $130(15.4)$ & $33(15.2)$ & $198(13.6)$ \\
\hline With later alert & $1,432(55.7)$ & $1,159(46.0)$ & $447(53.0)$ & $134(61.8)$ & $578(39.6)$ \\
\hline \multicolumn{6}{|c|}{ Infection/suspicion among users or family } \\
\hline No & $2,282(88.8)$ & $1,968(78.1)$ & $737(87.3)$ & $200(92.2)$ & $1,031(70.7)$ \\
\hline Yes & $287(11.2)$ & $552(21.9)$ & $107(12.7)$ & $17(7.8)$ & $428(29.3)$ \\
\hline \multicolumn{6}{|c|}{ Impact on staff employment } \\
\hline No & $937(36.5)$ & $1,208(47.9)$ & $409(48.5)$ & $94(43.3)$ & $705(48.3)$ \\
\hline Yes & $1,632(63.5)$ & $1,312(52.1)$ & $435(51.5)$ & $123(56.7)$ & $754(51.7)$ \\
\hline
\end{tabular}


Table 2. Associations between service types and usage restrictions

\begin{tabular}{|c|c|c|c|c|c|c|c|c|c|c|c|}
\hline & & \multicolumn{5}{|c|}{ Client cancellations } & \multicolumn{5}{|c|}{ Service contraction } \\
\hline & & $\mathrm{n}(\%)$ & OR & AOR & LLCI & ULCI & $\mathrm{n}(\%)$ & OR & AOR & LLCI & ULCI \\
\hline \multirow{15}{*}{$\begin{array}{l}\text { All services } \\
\quad(n=5,089)\end{array}$} & Service type & & & & & & & & & & \\
\hline & Home care & $1,816(72.1)$ & $5.65^{*}$ & $11.09^{*}$ & 9.14 & 13.46 & $1,062(42.1)$ & $1.18^{*}$ & $1.60^{*}$ & 1.36 & 1.89 \\
\hline & Service size & & & & & & & & & & \\
\hline & Small & $1,151(63.3)$ & Ref & Ref & & & $717(39.5)$ & Ref & Ref & & \\
\hline & Large & $823(43.2)$ & $0.44^{*}$ & $2.58^{*}$ & 2.07 & 3.23 & $863(45.3)$ & $1.27^{*}$ & $1.74^{*}$ & 1.44 & 2.10 \\
\hline & Area & & & & & & & & & & \\
\hline & With earlier alert & $1,079(61.7)$ & Ref & Ref & & & $881(50.4)$ & Ref & Ref & & \\
\hline & With mid alert & $390(52.0)$ & $0.67^{*}$ & $0.80^{*}$ & 0.66 & 0.98 & $312(41.6)$ & $0.70^{*}$ & $0.75^{*}$ & 0.63 & 0.89 \\
\hline & With later alert & $1,152(44.5)$ & $0.50^{*}$ & $0.64^{*}$ & 0.56 & 0.74 & $852(32.9)$ & $0.48^{*}$ & $0.55^{*}$ & 0.48 & 0.63 \\
\hline & Infection/suspicion among st & & & & & & & & & & \\
\hline & No & $2,550(51.1)$ & Ref & Ref & & & $1,980(39.7)$ & Ref & Ref & & \\
\hline & Yes & $71(68.9)$ & $2.12^{*}$ & 1.39 & 0.87 & 2.21 & $65(63.1)$ & $2.60^{*}$ & $1.64^{*}$ & 1.08 & 2.5 \\
\hline & Impact on staff employment & & & & & & & & & & \\
\hline & No & $959(44.7)$ & Ref & Ref & & & $656(30.6)$ & Ref & Ref & & \\
\hline & Yes & $1,662(56.5)$ & $1.60^{*}$ & $1.87^{*}$ & 1.63 & 2.14 & $1,389(47.2)$ & $2.03^{*}$ & $1.75^{*}$ & 1.54 & 1.98 \\
\hline \multirow{15}{*}{$\begin{array}{l}\text { Home care services } \\
\quad(\mathrm{n}=2,520)\end{array}$} & Service type & & & & & & & & & & \\
\hline & Adult day & $646(76.5)$ & Ref & Ref & & & $365(43.2)$ & Ref & Ref & & \\
\hline & Short stay & $111(51.2)$ & $0.32^{*}$ & $0.38^{*}$ & 0.26 & 0.57 & $116(53.5)$ & $1.51^{*}$ & $1.49^{*}$ & 1.02 & 2.16 \\
\hline & Home-visiting $(\mathrm{n}=1,549)$ & $1,059(72.6)$ & $0.81^{*}$ & $0.70^{*}$ & 0.57 & 0.87 & $581(39.8)$ & 0.87 & $0.72^{*}$ & 0.6 & 0.87 \\
\hline & With mid alert & $259(71.7)$ & $0.70^{*}$ & 0.77 & 0.58 & 1.03 & $153(42.4)$ & 0.8 & 0.81 & 0.63 & 1.03 \\
\hline & With later alert & $773(66.7)$ & $0.55^{*}$ & $0.67^{*}$ & 0.55 & 0.83 & $430(37.1)$ & $0.64^{*}$ & $0.68^{*}$ & 0.57 & 0.82 \\
\hline & Infection/suspicion among us & & & & & & & & & & \\
\hline & No & $1,343(68.2)$ & Ref & Ref & & & $783(39.8)$ & Ref & Ref & & \\
\hline & Yes & $473(85.7)$ & $2.79^{*}$ & $2.34^{*}$ & 1.78 & 3.06 & $279(50.5)$ & $1.55^{*}$ & $1.47^{*}$ & 1.19 & 1.8 \\
\hline & Infection/suspicion among st & & & & & & & & & & \\
\hline & No & $1,777(71.8)$ & Ref & Ref & & & $1,034(41.8)$ & Ref & Ref & & \\
\hline & Yes & $39(84.8)$ & $2.19^{*}$ & 1.13 & 0.48 & 2.64 & $28(60.9)$ & $2.17^{*}$ & 1.68 & 0.9 & 3.1 \\
\hline & Impact on staff employment & & & & & & & & & & \\
\hline & No & $785(65.0)$ & Ref & Ref & & & $421(34.9)$ & Ref & Ref & & \\
\hline & Yes & $1,031(78.6)$ & $1.98^{*}$ & $1.81^{*}$ & 1.5 & 2.18 & $641(48.9)$ & $1.79^{*}$ & $1.67^{*}$ & 1.42 & 1.98 \\
\hline
\end{tabular}

Multivariate logistic regression analysis (adjusted for the service size, area, infections/suspicion among users and family, infections/suspicion among staff, and impact on staff employment).

OR, (crude) odds ratio; AOR, adjusted odds ratio; LLCI/ULCI, lower/upper limit of the $95 \%$ confidential interval. ${ }^{*} \mathrm{p}<0.05$. 
likely to experience service contraction (AOR=1.49). The home visiting service was significantly less likely to have either client cancellations $(\mathrm{AOR}=0.70)$ and service contraction $(\mathrm{AOR}=0.72)$ than adult day services.

\section{Impact on Client Numbers and Revenue}

Table 3 shows the effects of client cancellations and service contracts on user numbers and revenue for each service. We observed no significant changes in the number of institutional care users but did observe significant revenue decreases related to client cancellations $(b=-0.014)$ and service contraction $(b=-0.019)$ in institutional LTC providers. Home care showed a significant decrease in the number of users $(b=-0.057)$ and income $(b=-0.049)$ related to service contraction.

In the adult day service, service contraction was associated with changes in user numbers $(b=-0.091)$ and revenue $(b=-0.071)$. We observed no significant changes in the short stay service. While the mean number of home visiting service users increased $(+0.5 \%)$, service contraction was associated with a significant reduction in revenue $(b=-0.034)$.

\section{DISCUSSION}

Home care was more likely to experience reduced usage than institutional care. It is difficult to suspend services for clients in an LTC facility and move them back to their homes or to another facility. In addition, clients in institutional care facilities had lower activities of daily living (ADLs) than those using home care; thus, it may have been difficult for them to postpone their admission and continue home care. This may have prevented reduced institutional usage especially that associated with client cancellation. We estimated that reduced institutional usage reduced revenues by $1.4 \%-$ $1.9 \%$. This was lower than that for home care, and reduced usage was assumed to occur in a limited number of patients.

In this study, $72 \%$ of home care providers experienced client cancellations, a rate significantly higher than that for institutional services. Although the government did not recommend avoiding the use of home-based services in general, clients may have perceived that the risk of infection from home care services exceeded the benefits of using them. In addition to health anxiety and risk to loved ones, regular media use and social media use were identified as predictors of fear related to COVID-19. ${ }^{17)}$ While the media are critical for conveying information to the public and promoting

Table 3. Changes in the number of users and revenue depending on usage restrictions by service

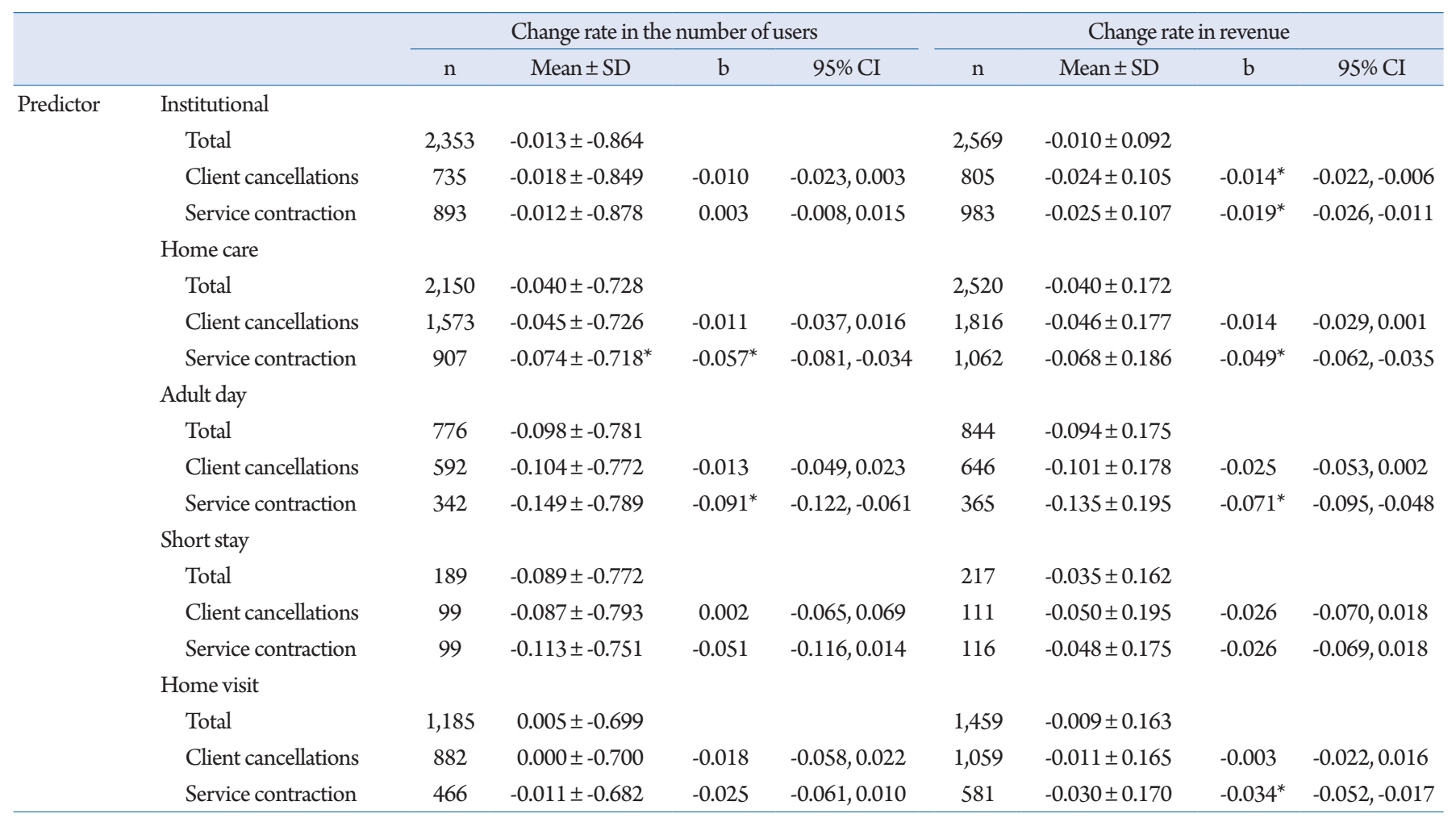

Multivariate linear regression analysis: clients' cancellation $(=1$, no $=0)$ and service contraction $(=1$, no $=0)$ as independent variables, adjusted for the service size. SD, standard deviation; CI, confidence interval. ${ }^{*} \mathrm{p}<0.05$. 
preventive behavior, information should be conveyed without sensationalism or disturbing images to avoid generating excessive fear. ${ }^{18)}$ The World Health Organization has also recommended that individuals limit seeking information from the media to about twice a day. ${ }^{19)}$ Additionally, service providers may have failed to adequately inform clients of the services' benefits and risks of service suspension. The purpose of LTC insurance is to provide health, medical, and welfare benefits for services necessary for clients to lead independent lives and maintain their dignity. ${ }^{20)}$ In this study, service providers were concerned about a potential decline in ADLs (68.9\% of respondents were concerned), fewer opportunities to go out and socialize $(59.2 \%)$, cognitive function decline (58.1\%), increased burden on family caregivers (57.3\%), and physical inactivity (42.3\%). ${ }^{16)}$ Emerging evidence has shown that community-dwelling older adults experienced negative effects on anxiety, depression, sleep quality, and physical activity during the period of social isolation due to COVID-19. ${ }^{21)}$ Insufficient communication on why home services are necessary and how they contribute to clients' health may have led to substantial underutilization. To avoid excessive client cancellations in future pandemics, it may be necessary to agree with clients and their families on the necessity and benefits of the regular use of home care services.

Among home care services, adult day services were more likely to experience reduced usage. Adult day service embeds social contact in its process. ${ }^{22,23)}$ Because clients often stay in the same place and eat at the same time in adult day services, it may have been difficult to take measures to prevent infection. Furthermore, since clients of adult day services have lower care needs on an average than short stay service clients, adult day services may have been temporarily replaced by informal caregiving or perceived as less necessary. The average increase in the number of home visit service users suggests that some clients reduced their use of adult day services and replaced these services with home visit services. Service contraction was more likely to occur in short stay services; however, as they were mostly located in LTC institutions with residents at higher risks of severe illness, they adopted more stringent preventive measures.

The adult day service experienced the largest impact on user numbers and revenue following reduced usage. We estimated that service contraction caused a $12.0 \%$ decrease in user numbers and a $7.2 \%$ decrease in revenue. Since the average profit ratio is $3.1 \%$ for all LTC providers and 3.3\% for adult day service, ${ }^{24)}$ a revenue reduction exceeding $10 \%$ could be critical. In this study, $19.9 \%$ of respondents reported increased expenditures related to additional infection control materials/ equipment and working hours; ${ }^{16)}$ thus, the impact on the profit ratio was likely greater. Home care providers are smaller enterprises than institutional care providers and therefore are likely to have less financial capacity. Although the proportion of service contractions was lower than that of client cancellations, it was much higher than the proportion of infected cases among service providers and users, suggesting that services were contracted in a fairly precautionary manner. As the pandemic continues, there has been progress in infection control training, including standard precautions and stocking of infection prevention items in home services. These efforts should continue to ensure service continuity as much as possible during future pandemics.

This study was conducted with an emphasis on timeliness, which limited the representativeness of the sample. It was difficult to survey facilities in crisis situations or that were closed due to outbreaks. Nevertheless, the results of the survey of care manag$\mathrm{ers}^{16)}$ also demonstrating that adult day services most commonly experienced service contraction, followed by short stay services and home-visiting services, suggests that this tendency is reliable.

The rates of change in client numbers and revenue are less reliable because the respondents were asked to retrospectively indicate the changes from the previous year. In addition, the rate of change was based on April data, while the usage restrictions were based on data at the time of the response (May 12-22); thus, there is a time gap. The results of this study should be followed up with further analyses of LTC insurance records and ongoing administrative survey data. Prolonged reduced usage may cause deterioration of physical and psychological outcomes, regardless of the COVID-19 situation. The potential long-term impact on the older population requires further investigation. In addition, the data did not include the condition of the affected clients (e.g., care level). This topic also requires further exploration as older people with higher care levels may be more vulnerable to the negative effects of service reduction.

\section{ACKNOWLEDGEMENTS}

The authors express their appreciation to the Japanese Council of Senior Citizens Welfare Service, Japan Association of Geriatric Health Service Facilities, Japan Association of Medical and Care Facilities, Zenkoku Syokibo Takinogata Kyotaku Kaigo Jigyosyo Renrakukai, Japan Group-Home Association for People with Dementia, Senior Housing Association (Japan), Japanese Association of Retirement Housing, Zenkoku Kaigo-tsuki homu kyokai, Japan Association of Day Care, The National Association for Visiting Nurse Service (Japan), Zenkoku Syakai-fukushi Hojin Keieisya Kyogikai, Minka Kaigo Jigyou Suishin Iinkai, Japanese Health and Welfare Co-operative Federation, Japan Workers' Co-operative Union, Japan Federation of Kaigo Business Providers, and the volunteers for their cooperation in this study. 


\section{CONFLICT OF INTEREST}

The researchers claim no conflicts of interest.

\section{FUNDING}

This study was supported by MEXT/JSPS KAKENHI (No. 20J11172).

\section{AUTHOR CONTRIBUTION}

Conceptualization, MK, SH; Data curation, HM, SH; Investigation, MK, SH; Methodology, HM; Project administration, MK, $\mathrm{SH}$; Supervision, $\mathrm{MK}$, SH; Writing-original draft, HM; Writing-review \& editing, $\mathrm{MK}, \mathrm{SH}$, and $\mathrm{HM}$.

\section{REFERENCES}

1. Lim WS, Liang CK, Assantachai P, Auyeung TW, Kang L, Lee WJ, et al. COVID-19 and older people in Asia: Asian Working Group for Sarcopenia calls to actions. Geriatr Gerontol Int 2020;20:547-58.

2. Simard J, Volicer L. Loneliness and isolation in long-term care and the COVID-19 pandemic. J Am Med Dir Assoc 2020;21: 966-7.

3. Chu CH, Donato-Woodger S, Dainton CJ. Competing crises: COVID-19 countermeasures and social isolation among older adults in long-term care. J Adv Nurs 2020;76:2456-9.

4. Omura T, Araki A, Shigemoto K, Toba K. Geriatric practice during and after the COVID-19 pandemic. Geriatr Gerontol Int 2020;20:735-7.

5. Yeung TA, Chan FH, Luk JK, Mok WY. COVID-19 and older adults: experience in Hong Kong. Asian J Gerontol Geriatr 2020;15:1-6.

6. Steinman MA, Perry L, Perissinotto CM. Meeting the care needs of older adults isolated at home during the COVID-19 pandemic. JAMA Intern Med 2020;180:819-20.

7. Dawson WD, Ashcroft EC, Lorenz-Dant K, Comas-Herrera A. Mitigating the impact of the COVID-19 outbreak: a review of international measures to support community-based care [Internet]. London, UK: International Long Term Care Policy Network; 2020 [cited 2021 Nov 11]. Available from: https://ltccovid.org/wp-content/uploads/2020/06/Community-BasedCare-Report-19-May.pdf.

8. Mahoney KJ. Self-direction of home and community-based services in the time of COVID-19. J Gerontol Soc Work 2020;63: 625-8.

9. Jang SN, Kim CO. Care inequality among older adults during the COVID-19 pandemic. Ann Geriatr Med Res 2020;24:22931.
10. Koh ZY, Law F, Chew J, Ali N, Lim WS. Impact of coronavirus disease on persons with dementia and their caregivers: an audit study. Ann Geriatr Med Res 2020;24:316-20.

11. Japan Federation of Kaigo Business Providers. Impact of the new coronavirus on the business situation [Internet]. Tokyo, Japan: Japan Federation of Kaigo Business Providers; 2020 [cited 2021 Nov 11]. Available from: http://kaiziren.or.jp/about/covid-19/.

12. Ministry of Health Labour and Welfare. Attention to prevent the spread of infection in social welfare facilities [Internet]. Tokyo, Japan: Ministry of Health Labour and Welfare; 2020 [cited 2021 Nov 11]. Available from: https://www.mhlw.go.jp/content/ 000601685.pdf.

13. Expert Committee on Pandemic Coronavirus Infection Control. Situation analysis and recommendations for the control of new coronavirus infections [Internet]. Tokyo, Japan: Ministry of Health Labour and Welfare; 2020 [cited 2021 Nov 11]. Available from: https://www.mhlw.go.jp/stf/seisakunitsuite/bunya/0000121431_00093.html.

14. Ministry of Health Labour and Welfare. Survey of the suspension of operations at disabled welfare service providers [Internet]. Tokyo, Japan: Ministry of Health Labour and Welfare; 2020 [cited 2021 Nov 11]. Available from: https://www.mhlw.go.jp/stf/ seisakunitsuite/bunya/0000121431_00097.html.

15. Iritani O, Okuno T, Hama D, Kane A, Kodera K, Morigaki K, et al. Clusters of COVID-19 in long-term care hospitals and facilities in Japan from 16 January to 9 May 2020. Geriatr Gerontol Int 2020;20:715-9.

16. Hitomachi Lab. Emergency survey on the effects of COVID-19 on care and support for the older adults and the approaches and efforts on the frontline [Internet]. [place unknown]: Hitomachi Lab; 2020 [cited 2021 Nov 11]. Available from: https://hitomachi-lab.com/archives/317/.

17. Mertens G, Gerritsen L, Duijndam S, Salemink E, Engelhard IM. Fear of the coronavirus (COVID-19): predictors in an online study conducted in March 2020. J Anxiety Disord 2020;74: 102258.

18. Garfin DR, Silver RC, Holman EA. The novel coronavirus (COVID-2019) outbreak: amplification of public health consequences by media exposure. Health Psychol 2020;39:355-7.

19. World Health Organization. Mental health and psychosocial considerations during the COVID-19 outbreak [Internet]. Geneva, Switzerland: World Health Organization; 2020 [cited 2021 Nov 11]. Available from: https://www.who.int/publications/i/item/mental-health-and-psychosocial-considerationsduring-the-covid-19-outbreak.

20. Masui H, Otaga M, Moriyama Y, Matsushige T. Current issues in long-term care policy and research: toward the promotion of ev- 
idence-based policy.J Natl Inst Public Health 2019;68:34-44.

21. Sepulveda-Loyola W, Rodriguez-Sanchez I, Perez-Rodriguez P, Ganz F, Torralba R, Oliveira DV, et al. Impact of social isolation due to COVID-19 on health in older people: mental and physical effects and recommendations. J Nutr Health Aging 2020;24: 938-47.

22. Orellana K, Manthorpe J, Tinker A. Day centres for older people: a systematically conducted scoping review of literature about their benefits, purposes and how they are perceived. Ageing Soc
2020;40:73-104.

23. Naruse T, Kitano A, Matsumoto H, Nagata S. A logic model for evaluation and planning in an adult day care for disabled Japanese old people. Int J Environ Res Public Health 2020;17:2061.

24. Ministry of Health Labour and Welfare. Business overview of long-term care providers in FY2019 [Internet]. Tokyo, Japan: Ministry of Health Labour and Welfare; 2019 [cited 2021 Nov 11]. Available from: https://www.mhlw.go.jp/toukei/list/1534a.html. 